\title{
Purinergic receptor P2Y, G-protein coupled, 2 (P2RY2) gene is associated with cerebral infarction in Japanese subjects
}

\author{
Zhaoxia Wang ${ }^{1,2}$, Tomohiro Nakayama ${ }^{1,3}$, Naoyuki Sato ${ }^{1}$, Mai Yamaguchi ${ }^{4}$, Yoichi Izumi $^{3}$, Yuji Kasamaki ${ }^{5}$, \\ Masakatsu Ohta ${ }^{5}$, Masayoshi Soma ${ }^{6}$, Noriko Aoi ${ }^{1}$, Yukio Ozawa ${ }^{5}$, Yitong $\mathrm{Ma}^{2}$, Nobutaka Doba ${ }^{7}$ and \\ Shigeaki Hinohara ${ }^{7}$
}

G-protein-coupled purinergic receptor P2Y2 (P2RY2) has an important role in the process of atherosclerosis related to cerebral infarction (Cl). The aim of this study was to investigate the relationship between the P2RY2 gene and $\mathrm{Cl}$ through a haplotypebased case-control study, including the separate analysis of two gender groups. A total of $237 \mathrm{Cl}$ patients and two control groups (control 1, 254; control 2, 255) were genotyped for five single nucleotide polymorphisms (SNPs) in the human P2RY2 gene (rs4944831, rs1783596, rs4944832, rs4382936, rs10898909). Among women, the distribution of the dominant rs4944832 phenotype (GG vs. GA+AA) differed significantly between the $\mathrm{Cl}$ patients and the control 1 group $(P=0.043)$ and between the $\mathrm{Cl}$ patients and the control 2 group $(P=0.029)$. Logistic regression analysis showed that the $\mathrm{GG}$ genotype of rs4944832 was significantly more prevalent in the female $\mathrm{Cl}$ patients than in the control $1(P=0.021)$ and control 2 groups $(P=0.005)$. For all subjects, the overall distribution of the haplotype established by rs1783596-rs4382936-rs10898909 was significantly different between the $\mathrm{Cl}$ patients and the control 1 group $(P=0.027)$. For all subjects, the frequency of the T-A-G haplotype (rs1783596-rs4382936-rs10898909) was also significantly higher $(P=0.031)$, whereas the frequency of the T-C-G haplotype (rs1783596-rs4382936-rs10898909) was significantly lower $(P=0.029)$ in the $\mathrm{Cl}$ patients than in the control 1 group. The present results indicate that the T-A-G haplotype of the human P2RY2 gene is a susceptibility haplotype for $\mathrm{Cl}$ in Japanese subjects, and that the GG genotype is a genetic marker for $\mathrm{Cl}$, particularly in Japanese women.

Hypertension Research (2009) 32, 989-996; doi:10.1038/hr.2009.136; published online 18 September 2009

Keywords: adenosine triphosphate; case-control study; haplotype; P2RY2; single nucleotide polymorphism

\section{INTRODUCTION}

Cerebral infarction (CI) is a leading cause of disability and death worldwide. Vascular neurologists have recently put forward a new 'universal' tissue definition of CI. ${ }^{1}$ This review proposes that CI be defined as brain or retinal cell death because of prolonged ischemia. It is generally accepted that atherosclerosis of the cerebral vessels induces cerebral ischemia. Some studies ${ }^{2}$ have shown that the proportion of causative factors for CI explained by genetic factors may be as large as 20 to $40 \%$, although diet, exercise and smoking remain critical risk factors. A number of polymorphisms in candidate genes are associated with atherosclerosis in certain populations and have been of considerable help in identifying CI susceptibility loci. ${ }^{3}$

Recently, the purinergic system has been shown to have an undisputed and crucial role in the modulation of vascular tone, and to be of similar importance as a regulator of the inflammatory response occurring in atherosclerosis. ${ }^{4}$ Purinergic receptors are ubiquitously expressed throughout the human body and are classified as $\mathrm{P} 1$ receptors and $\mathrm{P} 2$ receptors. $\mathrm{P} 2$ receptors include $\mathrm{P} 2 \mathrm{X}$ and $\mathrm{P} 2 \mathrm{Y}$ receptors, and the latter are seven-membrane span receptors coupled through $G$ proteins. At least eight $P 2 Y$ receptor subtypes (P2Y1, P2Y2, P2Y4, P2Y6, P2Y11, P2Y12, P2Y13 and P2Y14) have been identified ${ }^{5}$ in pharmacological and molecular cloning studies. The P2Y2 receptor, which is also referred to as P2RY2 (official name: purinergic receptor P2Y, G-protein coupled, 2), stimulates the growth of vascular smooth muscle cells (SMCs), endothelial cells and blood cells, and is involved in platelet aggregation and coagulation of regulation and inflammation, all of which are associated with the development of CI. ${ }^{6}$

\footnotetext{
${ }^{1}$ Division of Laboratory Medicine, Department of Pathology and Microbiology, Nihon University School of Medicine, Tokyo, Japan; ${ }^{2}$ Department of Cardiovascular Medicine, The First Affiliated Hospital of Xinjiang Medical University, Urumqi, Xinjiang, PR China; ${ }^{3}$ Division of Nephrology, Hypertension and Endocrinology, Department of Medicine, Nihon University School of Medicine, Tokyo, Japan; ${ }^{4}$ Division of Neurology, Department of Medicine, Nihon University School of Medicine, Tokyo, Japan; ${ }^{5}$ Division of Cardiovascular Medicine, Department of Medicine, Nihon University School of Medicine, Tokyo, Japan; ${ }^{6}$ Division of General Medicine, Department of Medicine, Nihon University School of Medicine, Tokyo, Japan and ${ }^{7}$ Life Planning Center, Tokyo, Japan

Correspondence: Dr T Nakayama, Division of Laboratory Medicine, Department of Pathology and Microbiology, Nihon University School of Medicine, 30-1 Ooyaguchi-kamimachi, Itabashi-ku, Tokyo 173-8610, Japan.

E-mail: tnakayam@med.nihon-u.ac.jp

Received 22 February 2009; revised 22 June 2009; accepted 22 July 2009; published online 18 September 2009
} 
Extracellular nucleotides, including adenosine triphosphate (ATP) and uridine triphosphate, that are released from a variety of arterial and blood cells can bind to P2RY2 on the cell surface. Activation of P2RY2 has been shown to induce both the proliferation and migration of vascular SMCs and apoptosis, a process involved in the evolution of atherosclerotic plaques. ${ }^{7}$ Some evidence suggests that P2RY2 is implicated in the development of vascular disease. ${ }^{8}$ Interestingly, a more recent study found that high shear stress, associated with vascular diseases, can selectively upregulate $\mathrm{P} 2 \mathrm{Y} 2$ receptors in perfused arterial SMCs. ${ }^{9}$ It has been proposed that upregulation of P2Y receptors is a potential diagnostic indicator for the early stages of atherosclerosis. ${ }^{10}$ A direct pathological role of P2RY2 is reinforced by recent evidence ${ }^{11}$ showing that the upregulation and activation of P2RY2 in rabbit arteries mediate the intimal hyperplasia that accompanies atherosclerosis. Guns et al. ${ }^{12}$ found that in the aorta of P2Y2-knockout mice, endothelium-dependent relaxation by ATP was inhibited, showing the role of P2RY2 in endothelial dysfunction. These studies show that the $\mathrm{P} 2 \mathrm{RY} 2$ gene has an important role in the process of atherosclerosis, the main cause of $\mathrm{CI}$.

To our knowledge, there have been no earlier studies on the association between the human P2RY2 gene and CI. This study was a retrospective haplotype-based case-control study. The aim was to investigate the association between the human P2RY2 gene and CI by using single nucleotide polymorphisms (SNPs) in conjunction with separate analyses of data pertaining to gender groups.

\section{METHODS}

\section{Subjects}

The study group consisted of $237 \mathrm{CI}$ patients (mean age, $63.2 \pm 12.8$ years, $\mathrm{m} / \mathrm{f}$ ratio=1.69). Subtypes of CI included thrombotic and lacunar stroke. Diagnosis was based on neurological examination and on the findings of computed tomography or magnetic resonance imaging, or both. In addition, all patients had neurological deficit ratings greater than grade 3 on the modified Rankin Scale. The study also enrolled 254 Japanese subjects as the control 1 group (mean age, $77.8 \pm 4.2$ years, $\mathrm{m} / \mathrm{f}$ ratio $=0.90$ ). All subjects were members of the New Elder Citizen Movement in Japan and resided in the Greater Tokyo Metropolitan Area. Although some of the subjects in the control 1 group had vascular risk factors such as hypertension, hypercholesterolemia and diabetes mellitus, none had a history of CI. All of the subjects in the control 1 group were confirmed to have grade 0 on the modified Rankin Scale of neurological deficits. Individuals with atrial fibrillation were excluded from both the $\mathrm{CI}$ and control groups. Participants with cancer or autoimmune disease, including antiphospholipid antibody syndrome, were also excluded..$^{13} \mathrm{~A}$ total of 255 sexmatched healthy individuals (mean age, $51.4 \pm 10.0$ years, $\mathrm{m} / \mathrm{f}$ ratio $=1.66$ ) were also enrolled as the control 2 group. None of the subjects in the control 2 group had a history of hypertension and CI, and all had systolic blood pressure $<130 \mathrm{~mm} \mathrm{Hg}$ and diastolic blood pressure $<85 \mathrm{~mm} \mathrm{Hg}$. The patients and two control groups were taking no medications influencing the adenylate cyclase pathway. Informed consent was obtained from each subject in accordance with the protocol approved by the Human Studies Committee of Nihon University. ${ }^{14}$ Sample sizes were considered to be appropriate for a case-control study. ${ }^{15}$

\section{Genotyping}

The human P2RY2 gene is located on chromosome 11q13.5-q14. 1, spans approximately $18.1 \mathrm{~kb}$, and contains three exons. There are 104 SNPs for the human P2RY2 gene listed in the National Center for Biotechnology Information SNP database Build 129 (http://www.ncbi.nlm.nih.gov/SNP). We screened the data for Tag SNPs on the International HapMap Project website (http:// www.hapmap.org/index.html.ja) using a cutoff level of $r^{2} \geqslant 0.5$. For minor allele frequencies, we used a cutoff level of $\leqslant 0.2$. According to the above criteria, we selected rs4944831 (SNP1, C-12034890-10, registration number by Applied Biosystems), rs1783596 (SNP2, C-8893575-10), rs4944832 (SNP3, C-27987464-10), rs4382936 (SNP4, C-1830488-20) and rs10898909 (SNP5, C-1830487-10) for

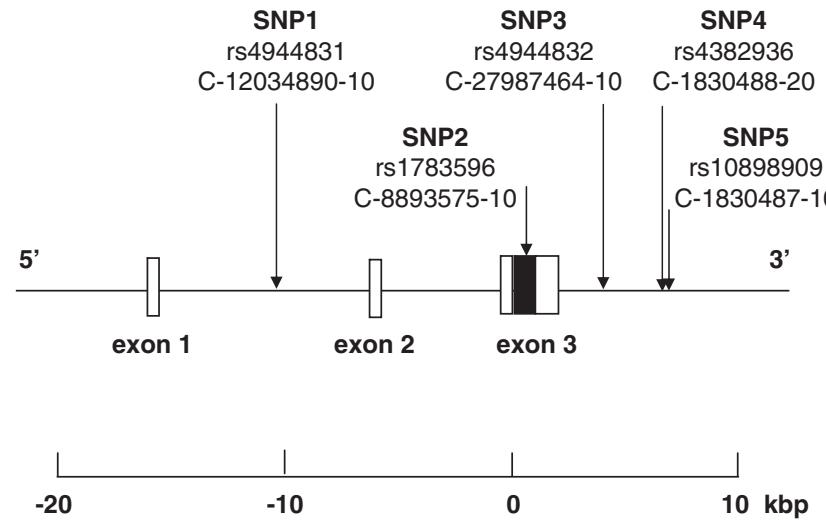

Figure 1 Structure of the human P2RY2 gene. The gene consists of three exons (boxes) separated by two introns. Lines show introns and intergenic regions. Filled box shows the coding region. Arrows indicate the locations of single nucleotide polymorphisms (SNPs). kbp, kilobase pairs.

this study (Figure 1). SNP1 was located in intron 1, whereas SNP2 was located in the coding region of exon 3. SNP3, SNP4 and SNP5 were located in the $3^{\prime}$ flanking region.

Blood samples were collected from all participants and genomic DNA was extracted from peripheral blood leukocytes by phenol and chloroform extraction.

Genotyping was performed using the TaqMan SNP Genotyping Assay (Applied Biosystems, Foster City, CA, USA). TaqMan SNP Genotyping Assays were performed by Taq amplification. ${ }^{16}$ In the $5^{\prime}$-nuclease assay, discrimination occurs during the polymerase chain reaction (PCR) because of allelespecific fluorogenic probes that, when hybridized to the template, are cleaved by the $5^{\prime}$-nuclease activity of Taq polymerase. The probes contain a $3^{\prime}$-minor groove-binding group that hybridizes to single-stranded targets with greater sequence-specificity than ordinary DNA probes. This reduces nonspecific probe hybridization, and results in low background fluorescence in the $5^{\prime}$ nuclease PCR assay (TaqMan; Applied Biosystems). Cleavage results in increased emission of a reporter dye. Each $5^{\prime}$-nuclease assay requires two unlabeled PCR primers and two allele-specific probes. Each probe is labeled with two reporter dyes at the $5^{\prime}$-end. In this study, VIC and FAM were used as reporter dyes. The primers and probes used in the TaqMan SNP Genotyping Assays (Applied Biosystems) were chosen on the basis of the information available on the Applied Biosystems website (http://www3.appliedbiosystems. com/AB_Home/index.htm).

PCR amplification was performed using $2.5 \mu \mathrm{l}$ of TaqMan Universal Master Mix, No. AmpErase UNG $(2 \times)$ (Applied Biosystems) in a $5-\mu$ l final reaction volume containing $2 \mathrm{ng}$ DNA, $0.046 \mu \mathrm{l}$ of TaqMan SNP Genotyping Assay Mix $(40 \times)$, primers at a concentration of $331.2 \mathrm{nmoll}^{-1}$ each, and probes at a final concentration of $73.6 \mathrm{nmoll}^{-1}$ each. Thermal cycling conditions consisted of $95^{\circ} \mathrm{C}$ for $10 \mathrm{~min}$, and then 50 cycles of $92^{\circ} \mathrm{C}$ for $15 \mathrm{~s}$ and $60^{\circ} \mathrm{C}$ for $1 \mathrm{~min}$ in a GeneAmp 9700 system (Applied Biosystems).

Each 96-well plate contained 80 DNA samples of an unknown genotype and four reaction mixtures containing reagents but no DNA (control samples). The control samples without DNA are a necessary part of the Sequence Detection System (SDS) 7700 signal processing, as outlined in the TaqMan Allelic Discrimination Guide (Applied Biosystems). Plates were read on the SDS 7700 instrument with the end-point analysis mode of the SDS version 1.6.3 software package (Applied Biosystems). Genotypes were determined visually on the basis of the dye-component fluorescent emission data depicted in the $\mathrm{X}-\mathrm{Y}$ scatter-plot of the SDS software. Genotypes were also determined automatically by the signal processing algorithms of the software. The results of each scoring method were saved in two separate output files for later comparison.

\section{Biochemical analysis}

We measured serum concentrations of creatinine using the standard methods used by the Clinical Laboratory Department of Nihon University Hospital. 


\section{Statistical analysis}

All continuous variables were expressed as means \pm s.d. Differences in continuous variables between the CI patients and controls were analyzed using the Mann-Whitney $U$-test. Differences in categorical variables were analyzed using Fisher's exact test. The Hardy-Weinberg equilibrium was assessed by $\chi^{2}$ analysis. Differences in the distributions of genotypes and alleles between the CI patients and controls were analyzed using Fisher's exact test. On the basis of the genotype data of the genetic variations, we performed linkage disequilibrium analysis and haplotype-based case-control analysis, using the expectation maximization algorithm ${ }^{17}$ and the software SNPAlyze version 3.2 (Dynacom, Yokohama, Japan). Pairwise linkage disequilibrium analysis was performed using five SNPs. We used $\left|\mathrm{D}^{\prime}\right|$ values greater than 0.5 to assign SNP locations to one haplotype block. SNPs with an $r^{2}$ value less than 0.5 were selected as tagged. In the haplotype-based case-control analysis, the frequency distribution of the haplotypes and $P$-values were calculated by $\chi^{2}$ analysis. In addition, logistic regression analysis was performed to assess the contribution of major risk factors. Statistical significance was established at $P$-values less than 0.05. Statistical analyses were performed using SPSS software for Windows (version 12; SPSS, Chicago, IL, USA).

\section{RESULTS}

Table 1 shows the clinical characteristics of the study participants. The mean age of the control 1 group was higher than that of the CI patients. In humans, the use of the so-called 'super controls' has been widely accepted in case-control studies for common diseases that appear later in life. ${ }^{13}$ Here, we used a 'super control' group, as healthy elderly subjects have been found to be more suitable than young or middle-aged subjects when determining phenotypes of cerebrovascular diseases related to aging. $\mathrm{CI}$ is an age-influenced disease, and the use of a 'super control' group rather than an age-matched control group is therefore better for increasing statistical power in these types of experiments. For the three groups, all subjects, men and women, the following values were significantly higher in the CI patients than in the two control groups: systolic blood pressure, diastolic blood pressure, and prevalence of hypertension and diabetes mellitus. For all subjects and men, serum creatinine and the prevalence of smoking and drinking and hyperlipidemia were significantly higher for the CI patients than for the control 1 group.

Table 2 shows the distributions of genotypes and alleles of the five SNPs. As the elderly subjects in the 'super-control' group may have had protective SNPs, and the patients and the control 1 group were not sex-matched, we added another group that was sex-matched and had a younger age (control 2 group). The genotype distribution of each SNP did not show significant differences from the Hardy-Weinberg equilibrium values in the control 1 and control 2 groups (data not shown). For women, the distribution of the dominant form of rs4944832 (GG vs. GA+AA) differed significantly between the $\mathrm{CI}$ patients and the control 1 group $(P=0.043)$, and between the $\mathrm{CI}$ patients and the control 2 group $(P=0.029)$. There were also significant differences in the allelic distribution of rs4944832 between the female CI patients and the control 1 group $(P=0.039)$, and between the female $\mathrm{CI}$ patients and the control 2 group $(P=0.017)$. Dominant and recessive models were defined by their overall frequency among controls. As similar results were seen in the control 2 group, we believe that the present 'super-elderly' subjects had no protective SNPs.

Table 3 shows the results of logistic regression analysis. As the relationship between rs4944832 and CI in women in Table 2 was not clear after using Bonferroni's correction, ${ }^{18}$ we examined this relationship by logistic regression analysis to confirm the results. For women, logistic regression was performed using the following parameters: GG genotype of rs4944832, pulse rate, creatinine with or without

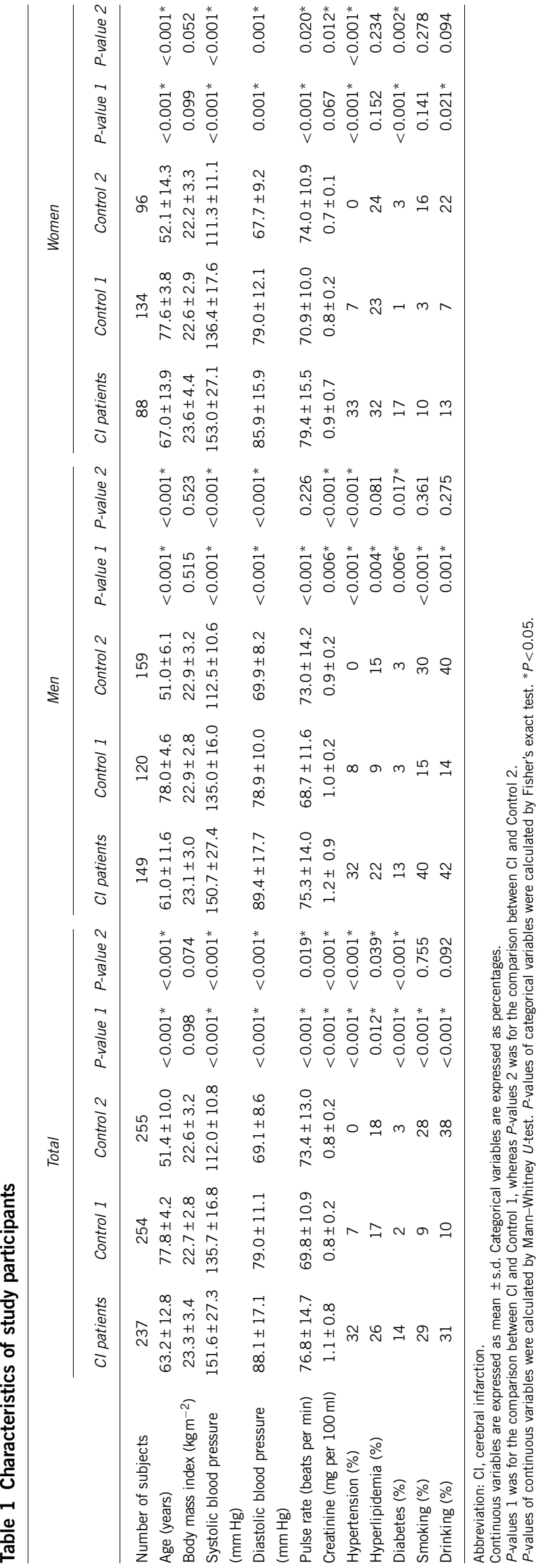




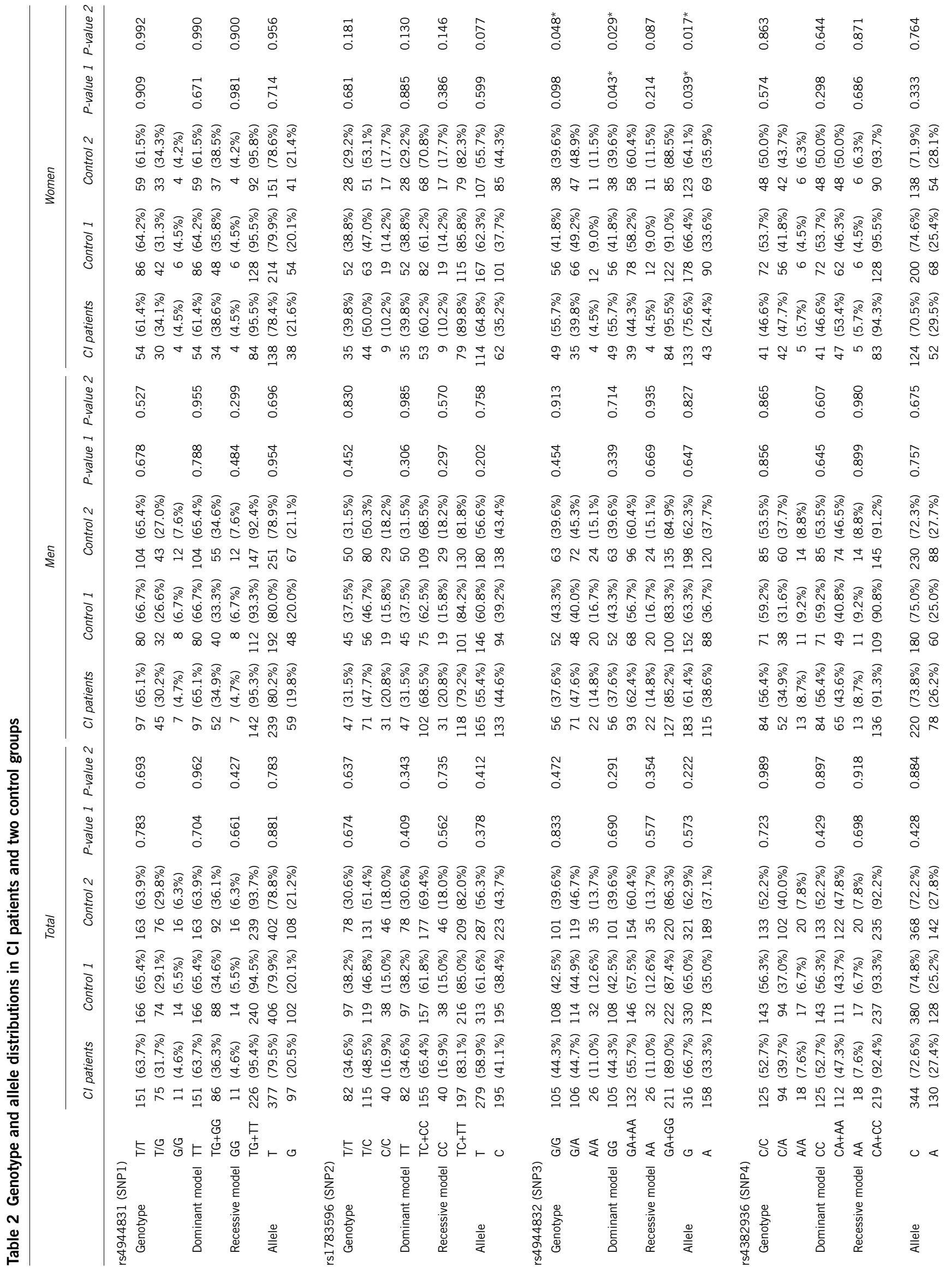




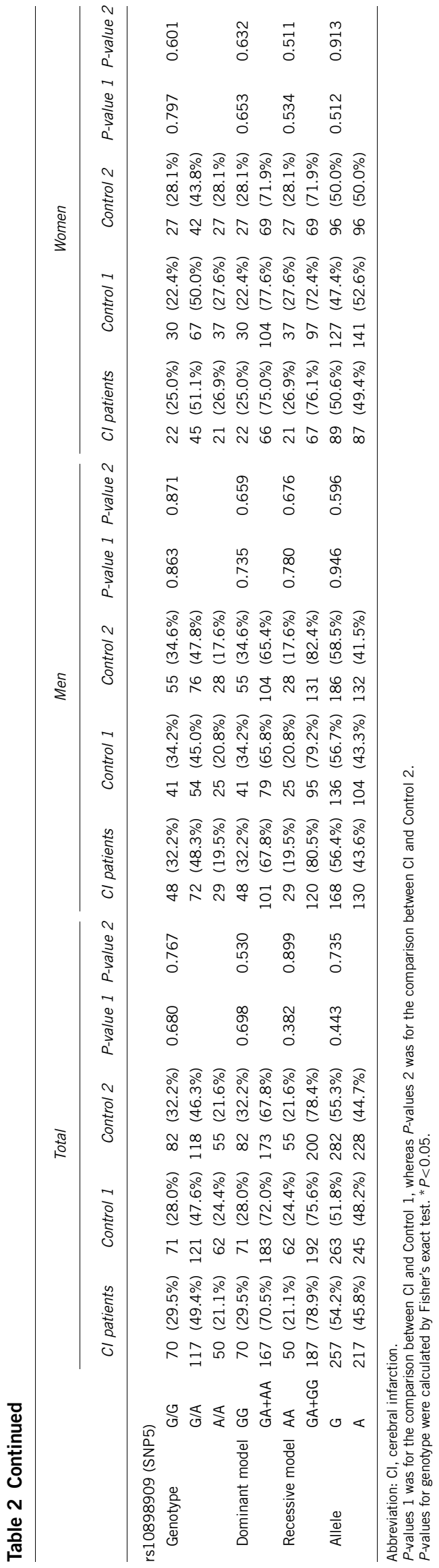

hypertension, diabetes mellitus or drinking frequency, because these confounding factors showed significant differences among women in Table 1 . The GG genotype of rs4944832 was found to be significantly higher in female $\mathrm{CI}$ patients than in the control 1 group $(P=0.021)$ and the control 2 group $(P=0.005)$, which further showed the relationship between rs4944832 and CI in women.

Figure 2 shows the patterns of linkage disequilibrium for the P2RY2 gene in the control 1 group, with their $\left|\mathrm{D}^{\prime}\right|$ and $r^{2}$ values. Four SNPs (SNP2, SNP3, SNP4 and SNP5) were located in one haplotype block, as the $\left|D^{\prime}\right|$ values were beyond 0.25 . However, SNP1 was not located in this haplotype block. As the $r^{2}$ values for SNP2-SNP3 were greater than 0.5, at least one SNP from SNP2 and SNP3 was suitable for the haplotype-based case-control study. Therefore, given that the minor allele frequency of SNP2 was larger than that of SNP3, we constructed the haplotypes using SNP2, SNP4 and SNP5.

In the haplotype-based case-control study, there were four combinations: SNP2-SNP4, SNP2-SNP5, SNP4-SNP5 and SNP2-SNP4SNP5 (Table 4). For all subjects, the overall distribution of the haplotype established by SNP2-SNP4-SNP5 was significantly different between the $\mathrm{CI}$ patients and the control 1 group $(P=0.027)$. For all subjects, the frequency of the T-A-G haplotype (SNP2-SNP4-SNP5) was also significantly higher $(P=0.031)$, whereas the frequency of the T-C-G haplotype (SNP2-SNP4-SNP5) was significantly lower $(P=0.029)$ for the CI patients than for the control 1 group. For women, the frequency of the T-A-A haplotype (SNP2-SNP4-SNP5) was significantly higher for the CI patients than for the control 1 group $(P=0.012)$.

\section{DISCUSSION}

In 1994, Parr et al. ${ }^{19}$ first reported the sequence and functional expression of cDNA-encoding P2RY2 cloned from airway epithelial cells, whereas in 1996, Dasari et al. ${ }^{20}$ mapped the human P2RY2 gene to chromosome 11q13.5-q14.1 using a PCR analysis of human-rodent hybrid cell line DNAs. Earlier studies in mice have identified important roles for P2RY2 in a variety of processes, including nucleotideregulated $\mathrm{Ca}^{2+}$ signaling in lung fibroblasts and airway epithelial cells, nucleotide-stimulated $\mathrm{Cl}^{-}$secretion in the trachea and gallbladder, neuronal growth, stimulation of $\mathrm{K}^{+}$secretion in the colon and neutrophil chemotaxis. ${ }^{21} \mathrm{P} 2 \mathrm{RY} 2$ may participate in various physiological responses by the activation of nucleotides. Extracellular ATP or UTP binds to P2RY2, and this combination activates phospholipase C and/or adenylate cyclase. ${ }^{22}$ In turn, phospholipase $\mathrm{C}$ activation generates inositol 1,4,5-triphosphate, a mediator of $\mathrm{Ca}^{2+}$ release from intracellular stores, and diacylglycerol, an activator of protein kinase $\mathrm{C}$, whereas adenylate cyclase generates cyclic adenosine monophosphate, an activator of protein kinase A.

Atherosclerosis related to $\mathrm{CI}$ is an immunoinflammatory process that involves complex interactions between the vessel wall and blood components and is thought to be initiated by endothelial dysfunction. ${ }^{23}$ From a vascular biology perspective, the processes of cellular adhesion, monocyte and macrophage attachment, and transmigration of immune cells across the endothelium are crucial steps in early atherogenesis and in the later stages of mature plaque rupture. ${ }^{24}$ Inflammatory cells express P2RY2 with multiple effects. P2RY2 is expressed on T lymphocytes and macrophages and has been suggested to be important in atherosclerosis. ${ }^{25}$ Recent studies have found an important role for P2RY2 in the development of intimal hyperplasia in rabbit carotid arteries. ${ }^{11}$ With regard to cerebral vessels, increased stroke risk has been associated with an increased rate of atherosclerosis progression in carotid vessels. Various evidence ${ }^{26,27}$ has also shown that $\mathrm{P} 2 \mathrm{Y} 2$ receptors in the smooth muscle cell mediate the dilation of 
Table 3 Odds ratios and 95\% confidence intervals for each risk factor, and GG genotype of rs4944832 associated with cerebral infarction in female subjects

\begin{tabular}{|c|c|c|c|c|c|c|c|}
\hline \multirow[b]{2}{*}{ Risk factor } & \multicolumn{3}{|c|}{ Control 1} & \multirow[b]{2}{*}{ Risk factor } & \multicolumn{3}{|c|}{ Control 2} \\
\hline & Odd ratios & $95 \%$ confidence interval & $P$-value & & Odd ratios & $95 \%$ confidence interval & $P$-value \\
\hline GG genotype & 4.185 & $1.237-14.159$ & $0.021 *$ & GG genotype & 3.317 & $1.423-7.733$ & $0.005^{*}$ \\
\hline Pulse rate & 1.022 & $0.969-1.078$ & 0.424 & Pulse rate & 1.038 & $1.004-1.073$ & $0.030 *$ \\
\hline Hypertension & 1.235 & $0.324-4.695$ & 0.757 & Hypertension & 2.173 & $0.811-4.824$ & 0.998 \\
\hline Diabetes mellitus & 5.917 & $0.999-34.483$ & 0.050 & Diabetes mellitus & 4.998 & 1.119-22.322 & $0.035^{*}$ \\
\hline Drinking & 1.331 & $0.186-9.508$ & 0.776 & Creatinine & 7.542 & $0.963-59.063$ & 0.054 \\
\hline
\end{tabular}

$* P<0.05$.

\begin{tabular}{|c|c|c|c|c|c|}
\hline SNP & & SNP2 & SNP3 & SNP4 & SNP5 \\
\hline \multirow{8}{*}{ SNP1 } & | D'| & 0.117 & 0.024 & 0.108 & 0.240 \\
\hline & $r^{2}$ & 0.006 & 0.000 & 0.009 & 0.013 \\
\hline & SNP2 & | D'| & 0.803 & 0.405 & 0.746 \\
\hline & & $r^{2}$ & 0.558 & 0.089 & 0.323 \\
\hline & & SNP3 & $\left|D^{\prime}\right|$ & 0.445 & 0.901 \\
\hline & & & $r^{2}$ & 0.124 & 0.408 \\
\hline & & & SNP4 & $\left|D^{\prime}\right|$ & 0.776 \\
\hline & & & & $r^{2}$ & 0.189 \\
\hline
\end{tabular}

$\left|D^{\prime}\right|>0.25$ $r^{2}>0.5$

Figure 2 Pairwise linkage disequilibrium (LD) in the human P2RY2 gene, as evaluated by $\left|D^{\prime}\right|$ and $r^{2}$ values. Pairwise LD was computed for the five marker pairs that were studied in the human P2RY2 gene. Pairs in LD $\left(\left|D^{\prime}\right| \geqslant 0.25\right.$ or $\left.r^{2} \geqslant 0.5\right)$ are shown as shaded values. rat cerebral arterioles. Marrelli et al. ${ }^{28}$ found that $\mathrm{P} 2 \mathrm{Y} 2$ receptors have an important role in the dilation of the rat's middle cerebral artery after ischemia reperfusion. These studies indicate that the P2RY2 gene has a close relationship with CI.

On the basis of the results of these animal studies, we planned to assess the association between the P2RY2 gene and CI using a haplotype-based case-control study. In this study, we found that the distribution of the dominant model of rs4944832 (GG vs. GA+AA) differed significantly between the female CI patients and the two control groups. The present results indicate that the risk of CI is increased in subjects with the GG genotype of rs4944832, which is associated with CI for Japanese women. We also found a significant difference in the allelic distribution of rs4944832 between the female CI patients and the two control groups. In this study, logistic regression analysis indicated that for women, the GG genotype of

Table 4 Haplotype analysis in $\mathrm{Cl}$ patients and control 1

\begin{tabular}{|c|c|c|c|c|c|c|c|c|c|c|c|c|c|c|c|}
\hline \multirow[b]{2}{*}{ Haplotype } & & & & \multicolumn{3}{|c|}{ Overall P-value } & \multicolumn{2}{|c|}{ Frequency in total } & \multirow[b]{2}{*}{$P$-value } & \multicolumn{2}{|c|}{ Frequency in men } & \multirow[b]{2}{*}{$P$-value } & \multicolumn{2}{|c|}{ Frequency in women } & \multirow[b]{2}{*}{$P$-value } \\
\hline & & & & Total & Men & Women & Cl patients & Control 1 & & Cl patients & Control 1 & & Cl patients & Control 1 & \\
\hline & SNP2 & SNP4 & & 0.217 & 0.179 & 0.662 & & & & & & & & & \\
\hline $\mathrm{H} 1$ & $\mathrm{~T}$ & $\mathrm{C}$ & & & & & 0.468 & 0.524 & 0.084 & 0.447 & 0.527 & 0.069 & 0.510 & 0.519 & 0.880 \\
\hline $\mathrm{H} 2$ & C & C & & & & & 0.257 & 0.224 & 0.227 & 0.291 & 0.223 & 0.079 & 0.195 & 0.228 & 0.387 \\
\hline H3 & C & A & & & & & 0.154 & 0.160 & 0.815 & 0.155 & 0.168 & 0.699 & 0.158 & 0.149 & 0.778 \\
\hline \multirow[t]{2}{*}{$\mathrm{H} 4$} & $\mathrm{~T}$ & A & & & & & 0.120 & 0.092 & 0.158 & 0.106 & 0.082 & 0.348 & 0.138 & 0.104 & 0.307 \\
\hline & SNP2 & & SNP5 & 0.823 & 0.279 & 0.704 & & & & & & & & & \\
\hline $\mathrm{H} 1$ & $\mathrm{~T}$ & & $A$ & & & & 0.412 & 0.435 & 0.454 & 0.397 & 0.418 & 0.627 & 0.212 & 0.173 & 0.308 \\
\hline $\mathrm{H} 2$ & C & & $\mathrm{G}$ & & & & 0.366 & 0.337 & 0.352 & 0.407 & 0.377 & 0.464 & 0.058 & 0.076 & 0.465 \\
\hline H3 & $\mathrm{T}$ & & $G$ & & & & 0.176 & 0.181 & 0.874 & 0.157 & 0.190 & 0.301 & 0.436 & 0.450 & 0.772 \\
\hline \multirow[t]{2}{*}{$\mathrm{H} 4$} & C & & A & & & & 0.046 & 0.047 & 0.951 & 0.039 & 0.015 & 0.109 & 0.294 & 0.301 & 0.879 \\
\hline & & SNP4 & SNP5 & 0.767 & 0.796 & 0.795 & & & & & & & & & \\
\hline $\mathrm{H} 1$ & & $\mathrm{C}$ & A & & & & 0.434 & 0.455 & 0.526 & 0.412 & 0.401 & 0.765 & 0.233 & 0.241 & 0.887 \\
\hline $\mathrm{H} 2$ & & C & $\mathrm{G}$ & & & & 0.292 & 0.293 & 0.941 & 0.326 & 0.349 & 0.550 & 0.472 & 0.506 & 0.460 \\
\hline $\mathrm{H} 3$ & & A & $\mathrm{G}$ & & & & 0.250 & 0.225 & 0.327 & 0.237 & 0.217 & 0.553 & 0.023 & 0.020 & 0.981 \\
\hline \multirow[t]{2}{*}{$\mathrm{H} 4$} & & A & $A$ & & & & 0.024 & 0.027 & 0.665 & 0.024 & 0.033 & 0.491 & 0.273 & 0.233 & 0.323 \\
\hline & SNP2 & SNP4 & SNP5 & $0.027^{*}$ & 0.118 & 0.076 & & & & & & & & & \\
\hline $\mathrm{H} 1$ & $\mathrm{~T}$ & $C$ & $A$ & & & & 0.394 & 0.408 & 0.679 & 0.378 & 0.385 & 0.922 & 0.056 & 0.091 & 0.205 \\
\hline $\mathrm{H} 2$ & C & C & $\mathrm{G}$ & & & & 0.221 & 0.180 & 0.114 & 0.251 & 0.214 & 0.286 & 0.049 & 0.075 & 0.327 \\
\hline $\mathrm{H} 3$ & C & A & $\mathrm{G}$ & & & & 0.144 & 0.157 & 0.539 & 0.156 & 0.163 & 0.797 & 0.013 & 0.001 & 0.080 \\
\hline $\mathrm{H} 4$ & $\mathrm{~T}$ & A & G & & & & 0.106 & 0.068 & $0.031^{*}$ & 0.081 & 0.054 & 0.230 & 0.011 & 0.020 & 0.546 \\
\hline $\mathrm{H} 5$ & $\mathrm{~T}$ & C & $\mathrm{G}$ & & & & 0.071 & 0.113 & $0.029 *$ & 0.075 & 0.136 & 0.115 & 0.421 & 0.431 & 0.857 \\
\hline H6 & C & $C$ & $A$ & & & & 0.039 & 0.047 & 0.584 & 0.034 & 0.015 & 0.221 & 0.178 & 0.150 & 0.450 \\
\hline $\mathrm{H} 7$ & $\mathrm{~T}$ & A & $A$ & & & & 0.018 & 0.028 & 0.258 & 0.019 & 0.033 & 0.339 & 0.159 & 0.082 & $0.012 *$ \\
\hline H8 & C & A & $A$ & & & & 0.006 & 0.000 & 0.073 & 0.050 & 0.000 & 0.204 & 0.113 & 0.151 & 0.283 \\
\hline
\end{tabular}

Abbreviation: $\mathrm{Cl}$, cerebral infarction.

Haplotypes were estimated using SNPAlyze software (version 3.2; Dynacom, Yokohama, Japan) $P$-values were calculated by $\chi^{2}$ analysis. ${ }^{*} P<0.05$ 
rs4944832 was significantly more common in the CI patients than in the two control groups. This indicates that the GG genotype is a genetic marker for CI in Japanese women.

Morris et al. ${ }^{29}$ found that for genes with multiple susceptibilities, analysis based on haplotypes has advantages over analysis based on individual SNPs, particularly when linkage disequilibria between the SNPs are weak. Consequently, in this study, we successfully established haplotypes for the P2RY2 gene from the various combinations of the three selected SNPs. For the present haplotype analysis, although there were significant differences in the frequency of the T-A-A haplotype (SNP2-SNP4-SNP5) between the female CI patients and the control 1 group, we believe that this difference is not particularly important, as the overall distribution of the combination (SNP2-SNP4-SNP5) for women did not significantly differ between the CI patients and the control 1 group $(P=0.076)$. In this study, for all subjects, the frequency of the T-A-G haplotype was significantly higher for the CI patients than for the control 1 group, and the T-A-G haplotype can be regarded as a susceptibility haplotype for CI in Japanese subjects. The frequency of the T-C-G haplotype was significantly lower for the CI patients than for the control 1 group, and the T-C-G haplotype can be regarded as a resistance haplotype for $\mathrm{CI}$ in Japanese subjects.

In this study, the GG genotype of rs4944832 showed a genderspecific significant difference (for women only). Although being male is recognized as a risk factor for $\mathrm{CI}$, some basic and clinical studies have shown the opposite results. ${ }^{30,31}$ ATP, the ligand for P2RY2, has been shown to increase the production of progesterone and estradiol in human granulosa-luteal cells. ${ }^{32}$ Several clinical and experimental studies have suggested that estrogen is not universally neuroprotective in experimental cerebral ischemia ${ }^{31}$ and may not be beneficial for ischemic preconditioning in experimental ischemia models. ${ }^{33}$ Recent clinical studies have suggested that there are unanticipated and paradoxical effects of estrogen and hormone replacement therapy relative to stroke risk, as it is currently administered to women. ${ }^{34}$ One study has suggested that women on hormone replacement therapy have a higher risk of perioperative stroke. ${ }^{35}$ Therefore, depending on the ischemic conditions present and the level of ATP, estrogen has the ability to harm ischemically compromised brain tissue.

In conclusion, the T-A-G haplotype of the human P2RY2 gene may be a susceptibility haplotype for CI in Japanese subjects, and the GG genotype could be a genetic marker for CI, particularly in Japanese women. This study also shows that the T-C-G haplotype is a resistance marker for $\mathrm{CI}$ in Japanese subjects. Further studies are needed to isolate functional mutations in the P2RY2 gene that modulate the process of atherosclerosis, and to evaluate the function of P2RY2 variants that are involved in the metabolism of sex hormones.

\section{ACKNOWLEDGEMENTS}

We thank Ms K Sugama for her technical assistance. This work was supported by grants from Toray Co., Ltd. and the Ministry of Education, Culture, Sports, Science and Technology of Japan (High-Tech Research Center, Nihon University).

1 Saver JL. Proposal for a universal definition of cerebral infarction. Stroke 2008; 39: 3110-3115.

2 Ridker PM, Silvertown JD. Inflammation, C-reactive protein, and atherothrombosis. J Periodontol 2008; 79: 1544-1551.
3 Kaneko Y, Nakayama T, Saito K, Morita A, Sato I, Maruyama A, Soma M, Takahashi T, Sato N. Relationship between the thromboxane A2 receptor gene and susceptibility to cerebral infarction. Hypertens Res 2006; 29: 665-671.

4 Gachet C. Regulation of platelet functions by P2 receptors. Annu Rev Pharmacol Toxicol 2006; 46: 277-300.

5 Burnstock G. Physiology and pathophysiology of purinergic neurotransmission. Physio Rev 2007; 87: 659-797.

6 Webb TE, Boluyt MO, Barnard EA. Molecular biology of P2Y purinoceptors: expression in rat heart. J Auton Pharmacol 1996; 16: 303-307.

7 Isner JM, Kearney M, Bortman S, Passeri J. Apoptosis in human atherosclerosis and restenosis. Circulation 1995; 91: 2703-2711.

8 Di Virgilio F, Solini A. P2 receptors: new potential players in atherosclerosis. $\mathrm{Br} J$ Pharmacol 2002; 135: 831-842.

9 Wang L, Andersson M, Karlsson L, Watson MA, Cousens DJ, Jern S, Erlinge D. Increased mitogenic and decreased contractile P2 receptors in smooth muscle cells by shear stress in human vessels with intact endothelium. Arterioscler Thromb Vasc Biol 2003; 23: 1370-1376

10 Elmaleh DR, Narula J, Babich JW, Petrov A, Fischman AJ, Khaw BA, Rapaport E, Zamecnik PC. Rapid noninvasive detection of experimental atherosclerotic lesions with novel 99mTc-labeled diadenosine tetraphosphates. Proc Natl Acad Sci USA 1998; 95: 691-695.

11 Seye $\mathrm{Cl}$, Kong Q, Erb L, Garrad RC, Krugh B, Wang M, Turner JT, Sturek M, González FA, Weisman GA. Functional P2Y2 nucleotide receptors mediate uridine 5'-triphosphate-induced intimal hyperplasia in collared rabbit carotid arteries. Circulation 2002; 106: 2720-2726.

12 Guns PJ, Van Assche T, Fransen P, Robaye B, Boeynaems JM, Bult H. Endotheliumdependent relaxation evoked by ATP and UTP in the aorta of P2Y2-deficient mice. Br J Pharmacol 2006; 147: 569-574.

13 Morita A, Nakayama T, Doba N, Hinohara S, Soma M. Polymorphism of the C-reactive protein (CRP) gene is related to serum CRP Level and arterial pulse wave velocity in healthy elderly Japanese. Hypertens Res 2006; 29: 323-331.

14 Aoi N Soma M, Nakayama T, Rahmutula D, Kosuge K, Izumi Y, Matsumoto K. Variable number of tandem repeat of the $5^{\prime}$-flanking region of type-C human natriuretic peptide receptor gene influences blood pressure levels in obesity-associated hypertension. Hypertens Res 2004; 27: 711-716.

15 Olson JM, Wijsman EM. Design and sample-size considerations in the detection of linkage disequilibrium with a disease locus. Am J Hum Genet 1994; 55: 574-580.

16 Kobayashi Y, Nakayama T, Sato N, Izumi Y, Kokubun S, Soma M. Haplotype-based case-control study revealing an association between the adrenomedullin gene and proteinuria in subjects with essential hypertension. Hypertens Res 2005; 28 : 229-236.

17 Naganuma T, Nakayama T, Sato N, Fu Z, Soma M, Aoi N, Usami R. A haplotype-based case-control study examining human extracellular superoxide dismutase gene and essential hypertension. Hypertens Res 2008; 31: 1533-1540.

18 Gyorffy B, Gyorffy A, Tulassay Z. The problem of multiple testing and solutions for genome-wide studies. Orv Hetil 2005; 146: 559-563.

19 Parr CE, Sullivan DM, Paradiso AM, Lazarowski ER, Burch LH, Olsen JC, Erb L, Weisman GA, Boucher RC, Turner JT. Cloning and expression of a human P2U nucleotide receptor, a target for cystic fibrosis pharmacology. Proc Natl Acad Sci USA 1994; 91: 3275-3279.

20 Dasari VR, Sandhu AK, Mills DC, Athwal RS, Kunapuli SP. Mapping of the P2U purinergic receptor gene to human chromosome 11q 13.5-14.1. Somat Cell Mol Genet 1996; 22: 75-79.

21 Rieg T, Bundey RA, Chen Y, Deschenes G, Junger W, Insel PA, Vallon V. Mice lacking $\mathrm{P} 2 \mathrm{Y} 2$ receptors have salt-resistant hypertension and facilitated renal $\mathrm{Na}^{+}$and water Reabsorption. FASEB J 2007; 21: 3717-3726

22 Von Kugelgen I, Wetter A. Molecular pharmacology of P2Y receptors. Naunyn Schmiedeberg's Arch Pharmacol 2000; 362: 310-323.

23 Takei Y, Tomiyama H, Tanaka N, Yamashina A. Close relationship between sympathetic activation and coronary microvascular dysfunction during acute hyperglycemia in subjects with atherosclerotic risk factors. Circ J 2007; 71: 202-206.

24 Hollan I, Prayson R, Saatvedt K, Almdahl SM, Nossent HC, Mikkelsen K, Liang MH, Kvelstad IL, Aamodt G, Forre OT. Inflammatory cell infiltrates in vessels with different susceptibility to atherosclerosis in rheumatic and non-rheumatic patients. Circ J 2008; 72: 1986-1992.

25 Di Virgilio F, Solini A. P2 receptors: new potential players in atherosclerosis. $\mathrm{Br} \mathrm{J}$ Pharmacol 2002; 135: 831-842.

26 Horiuchi T, Dietrich HH, Hongo K, Dacey Jr RG. Comparison of P2 receptor subtypes producing dilation in rat intracerebral arterioles. Stroke 2003; 34: 1473-1478.

27 Horiuchi T, Dietrich HH, Tsugane S, Dacey Jr RG. Analysis of purine- and pyrimidineinduced vascular responses in the isolated rat cerebral arteriole. Am J Physiol Heart Circ Physiol 2001; 280: H767-H776.

28 Marrelli SP, Khorovets A, Johnson TD, Childres WF, Bryan Jr RM. P2 purinoceptormediated dilations in the rat middle cerebral artery after ischemia-reperfusion. Am J Physiol 1999; 276: H33-H41.

29 Morris RW, Kaplan NL. On the advantage of haplotype analysis in the presence of multiple disease susceptibility alleles. Genet Epidemiol 2002; 23: 221-233.

30 Wang L, Kitano H, Hurn PD, Murphy SJ. Estradiol attenuates neuroprotective benefits of isoflurane preconditioning in ischemic mouse brain. J Cereb Blood Flow Metab 2008; 28: 1824-1834.

31 Macrae IM, Carswell HV. Oestrogen and stroke: the potential for harm as well as benefit. Biochem Soc Trans 2006; 34: 1362-1365. 
32 Kamada S, Blackmore PF, Oehninger S, Gordon K, Hodgen GD. Existence of P2purinoceptors on human and porcine granulosa cells. J Clin Endocrinol Metab 1994; 78: 650-656.

33 Song X, Li G, Vaage J, Valen G. Effects of sex, gonadectomy, and oestrogen substitution on ischaemic preconditioning and ischaemia-reperfusion injury in mice. Acta Physiol Scand 2003; 177: 459-466.
34 Grodstein F, Manson JE, Colditz GA, Willett WC, Speizer FE, Stampfer MJ. A prospective, observational study of postmenopausal hormone therapy and primary prevention of cardiovascular disease. Ann Intern Med 2000; 133: 933-941.

35 Lane JS, Shekherdimian S, Moore WS. Does female gender or hormone replacement therapy affect early or late outcome after carotid endarterectomy? J Vasc Surg 2003; 37: 568-574. 